\title{
Value at Risk as a Tool for Mutual Funds Performance Evaluation
}

\author{
Reza Tehrani ${ }^{1}$, Saeed Mirza Mohammadi ${ }^{2} \&$ Neda Sadat Nejadolhosseini ${ }^{1}$ \\ ${ }^{1}$ Department of Management, University of Tehran, Tehran, Iran \\ ${ }^{2}$ School of Industrial Engineering, University of Science and technology, Tehran, Iran \\ Correspondence: Neda Sadat Nejadolhosseini, Department of Management, University of Tehran, Tehran, P.O. \\ Box 6311-14155, Iran. Tel: 98-764-445-4547. E-mail: n_nhosseini@ut.ac.ir
}

Received: July 21, 2014

Accepted: August 11, 2014

Online Published: September 25, 2014

doi:10.5539/ibr.v7n10p16

URL: http://dx.doi.org/10.5539/ibr.v7n10p16

\begin{abstract}
The present study addressed the measurement of one-day-ahead Value at Risk (VaR) of Iranian mutual funds using GARCH parametric method and Monte Carlo Simulation non-parametric method. The Kupiec back testing results showed that both methods enjoy a high level of accuracy but based on simplified assumption of return distribution function in the parametric approach; Monte Carlo simulation produced better results. Furthermore, the adjusted Sharpe ratio and VaR were used to investigate the performance evaluation of the mutual funds.
\end{abstract}

Keywords: back-testing, downside risk, Monte Carlo Simulation, mutual funds, performance evaluation, Value at Risk (VaR)

\section{Introduction}

All types of investments, including mutual funds, involve risk. Higher risks are usually taken with the expectation of gaining higher returns at the cost of increased volatility so this results in the risk/return trade-off. In the last few years, mutual funds in Iran have attracted a lot of investments. To select the appropriate fund, investors need suitable performance evaluation methods to take the correct decision based on their risk.

Market risk is primarily estimated using position-based risk measures such as Value at Risk (VaR). VaR is applied to different kinds of financial instruments such as stock, bonds, foreign exchange, and derivative financial instruments. VaR is a statistical measure of total portfolio risk, based on the most current positions, which takes into account portfolio diversification and leverage (Jorion, 2009). Following the lead from both regulators and large international banks during the mid-1990s, almost all financial institutions now use some form of VaR as a risk metric. This almost universal adoption of VaR has sparked much controverdy (Alexander, 2008). Whilst VaR has become a universal risk metric used by banks and also by non-financial corporations, fund managers traditionally used quite different metrics (Alexander, 2008). Value at Risk measures the worst expected loss under normal market conditions over a specific time interval at a given confidence level.Alternatively, $\mathrm{VaR}$ is the lowest quantile of the potential losses that may occur within a given portfolio during a specified time period (Benninga, 2008). VaR is a quantile risk metric. However, when returns are normal, each quantile is just a multiple of standard deviation. As such, in this special case, VaR obeys the same rules as the standard deviation. Otherwise, VaR does not obey nice rules and it may not even be sub-additive (Alexander, 2008). Perhaps the greatest advantage of VaR is that it summarizes in a single, easy to understand number of the downside risk of an institution due to financial market variable. No doubt, this explains why VaR is fast becoming an essential tool for conveying trading risks to senior management, directors, and shareholders (Jorion, 2007).

To calculate VaR, a number of methods such as parametric, historical simulation, and Monte Carlo simulation can be used.

Wiener (2012) used VaR approach based on queuing theory to evaluate risk measurement systems and optimizing the selection process in banks. Bryant and Liu (2011), Zhao et al. (2011), and Cullen et al. (2012) investigated risk associated withmutual funds. Białkowskia and Otten (2011) studied the performance of mutual funds in Poland. Eling (2008) compared different performance measures for fund evaluations. Deb and Barenjee (2009) used three parametric models and one non parametric model for equity mutual funds in India to predict their weekly VaR. They also employed two back testing approaches. Gallsli and Guesmi (2008) compared parametric method, historical simulation, and Monte Carlo simulation to determine the most pertinent 
methodology of VaR in 14 Tunisian open-end funds portfolios. The results pointed to the Monte Carlo simulation superiority over the two other approaches. Weng and Trück (2011) identified risk factors for Asia-focused hedge funds through a modified style analysis technique to provide appropriate forecasts for volatility and Value-at-Risk of the index. They further evaluated the performance of thesemodels with respect to VaR estimation. Feng (2008) used traditional Sharpe index with standard deviation as a risk variable compared to VaR as the substitute for standard deviation in Chinese mutual funds to find a better fund performance measure.

In this paper, the value at risk of mutual fund is calculated by parametric and non-parametric methods. The remainder of the paper is structured as follows. Section 2 describes the method and state the problem, Section 3 presents the data analysis, and finally Section 4 discusses the results of the study.

\section{Method}

The sample data included daily returns of Iran mutual funds active from 2009 to 2012 and were calculated as follows:

$$
r_{t}=\operatorname{Ln}\left(N A V_{t} / N A V_{t-1}\right)
$$

$\mathrm{VaR}$ is a loss that we are fairly sure will not be exceeded if the current portfolio is held over some period of time. When VaR is estimated from a return distribution, it is expressed as a percentage of the portfolio's current value. Since the current value of the portfolio is observable, it is not regarded as a random variable (Alexander, 2008). The calculation methods of VaR in literature have been divided into parametric and non-parametric methods.

\subsection{GARCH Method to Estimate VaR}

Normality assumption of returns seems to be in conflict with the empirical properties of most financial time series. We can use methods that try to relax the strong assumption of normality. The parametric methods assume a specific distribution of returns. They use estimation methods like maximum likelihood estimation (MLE) to measure the relevant parameters of the distribution, which are then used to forecast the future return distribution and VaR as well. Following Engle's research (1982), Bollerslev developed the generalized autoregressive conditional heteroskedasticity (GARCH) model in 1986. This relatively simple statistical analysis is used to discover the existence of any clustering behavior in volatility. It is also possible to observe any leptokurtosis effects in the distribution of returns. The GARCH $(1,1)$ framework is the simplest and most popular model available through Bollerslev work. This framework is used to define the conditional mean and variance as follows (Gregoriou, 2009):

$$
\begin{gathered}
X_{t}=\mu+\sigma_{t} \varepsilon_{t} \\
\sigma_{t}^{2}=\omega+\beta \sigma_{t-1}^{2}+\gamma \sigma_{t-1}^{2} \varepsilon_{t-1}^{2} \text { with } \omega>0, \beta \geq 0, \\
\gamma>0, \text { and } \beta+\gamma<0
\end{gathered}
$$

Eventually, VaR is calculated as follows (Alexander, 2008):

$$
\operatorname{VaR}_{a}=\phi^{-1}(1-\alpha) \sigma-\mu
$$

\subsection{Monte Carlo Simulation to Estimate VaR}

Monte Carlo simulation is more flexible than parametric models. As with historical simulation, Monte Carlo simulation allows the risk manager to use actual historical distributions for risk factor returns. A large number of randomly generated simulations are run forward in time using volatility and correlation estimates chosen by the risk manager. Each simulation will be different but, in total, the simulations will aggregate to the chosen statistical parameters. This method is more realistic and, therefore, is more likely to estimate VaR more accurately (Choudhry, 2006).

\subsection{Kupiec Test}

The first logical way to evaluate prediction ability of VaR model is counting the number of times in which the real loss is greater than the predicted loss by VaR. If VaR is independent, the comparison of the real results estimated by this model will be considered successful in terms of correctness and vice versa. We define failure and success as an event. The relevant null hypothesis is $\mathrm{H}_{0}: \mathrm{a}=\mathrm{a}_{0}$. Further, the appropriate likelihood return statistic is asymptotically distributed as a chi-squared distribution (Gregoriou, 2009):

$$
L R_{P F}=2\left[\ln \left(a^{x}(1-a)^{T-x}\right)-\ln \left(a_{0}^{x}\left(1-a_{0}\right)^{T-x}\right)\right]
$$

Unfortunately, as Kupiec observed, these tests have a limited ability in distinguishing among alternative hypotheses. However, these approaches have been employed by regulators for the analysis of internal models in which the different models are categorized in back testing (Gregoriou, 2009). 


\section{Results}

Firstly, time series are examined with respect to stationary data and autocorrelation. The result of augmented Dickey-Fuller test allows us to affirm that funds returns present stationary series. The value of Durbin-Watson test for the sample funds is between 1.94 to 2.019 or approximately equal to 2, indicating no serial correlation.

Using GARCH method, conditional mean, conditional variance, and VaR is calculated at confidence levels of $99 \%$ and $95 \%$.

Table 1. Estimation of VaR using GARCH $(1,1)$

\begin{tabular}{|c|c|c|c|c|}
\hline Mutual Fund & Conditional Mean & Conditional & $\operatorname{VaR}(=0.01)$ & $\operatorname{VaR}(=0.05)$ \\
\hline Amin Global & 0.055 & 0.164 & -0.327 & -0.215 \\
\hline Arian & 0.085 & 0.676 & -1.489 & -1.027 \\
\hline Agah & 0.1 & 0.438 & -0.92 & -0.621 \\
\hline Novin Bank & 0.104 & 0.723 & -1.578 & -1.085 \\
\hline Tejarat Bank & 0.137 & 0.311 & -0.587 & -0.375 \\
\hline Saderat Bank & 0.14 & 0.735 & -1.57 & -1.069 \\
\hline Melli Bank & 0.055 & 0.517 & -1.149 & -0.796 \\
\hline Bourse Bime & 0.105 & 1.12 & -2.5 & -1.737 \\
\hline Boursiran & 0.105 & 0.589 & -1.265 & -0.863 \\
\hline Pasargad & 0.094 & 0.988 & -2.205 & -1.531 \\
\hline Pooya & 0.105 & 0.699 & -1.522 & -1.046 \\
\hline Pishtaz & 0.137 & 0.49 & -1.003 & -0.669 \\
\hline Pishgam & 0.061 & 0.541 & -1.199 & -0.83 \\
\hline Hafez & 0.086 & 0.478 & -1.026 & -0.7 \\
\hline Khobregan & 0.102 & 0.295 & -0.584 & -0.383 \\
\hline Razavi & 0.067 & 1.147 & -2.602 & -1.82 \\
\hline Sahm Ashna & 0.114 & 0.662 & -1.427 & -0.976 \\
\hline Shadab & 0.034 & 0.715 & -1.629 & -1.141 \\
\hline Kaspian Mehr & 0.044 & 0.538 & -1.209 & -0.842 \\
\hline Yekom Iranian & 0.047 & 0.389 & -0.859 & -0.594 \\
\hline
\end{tabular}

To use Monte Carlo simulation, it is needed to fit the best distribution function on the existing data. For good of fitness test, chi-square test and Kolmogorov-Smirnov test were applied. The resulting distribution function and parameter values are shown in Table 2. Based on the daily limitation of stock price volatility, the fund returns including the portfolio of stock have little volatility too. Most of the daily returns are near zero and return distribution function is inclined from normal to distribution functions as Laplas and Cauchy. After determining distribution function in each fund, 1000 numbers were produced randomly by fitted distribution function and VaR was calculated. Then, to increase the accuracy of calculations, this was repeated 100 times and final VAR of average of one-hundred VaR was obtained. 
Table 2. Estimation of VaR using Monte Carlo simulation

\begin{tabular}{llcc}
\hline Mutual Fund & Fitted Distribution Function & VaR $(=0.01)$ & VaR $(=0.05)$ \\
\hline Amin Global & Cauchy $(=0.0687, \mu=0.04744)$ & -0.646 & -0.265 \\
Arian & Cauchy $(=0.225, \mu=0.0468)$ & -2.533 & -1.029 \\
Agah & Laplace $(=3.4352, \mu=0.0602)$ & -1.085 & -0.617 \\
Eghtesad.novin Bank & Cauchy $(=0.225, \mu=0.0468)$ & -1.085 & -0.617 \\
Tejarat Bank & Error $(\mathrm{k}=1,=0.4051, \mu=0.1014)$ & -0.984 & -0.556 \\
Saderat Bank & Laplace $(=2.5498, \mu=0.0937)$ & -1.432 & -0.812 \\
Melli Bank & Cauchy $(=0.2447, \mu=0.02796)$ & -1.11 \\
Bourse Bime & Error $(\mathrm{k}=1.3,=0.5116, \mu=0.0906)$ & -2.622 & -0.952 \\
Boursiran & Laplace $(=2.8287, \mu=0.08098$ & -1.595 & -0.729 \\
Pasargad & Cauchy $(=0.2678, \mu=0.0437)$ & -1.286 & -1.082 \\
Pooya & Error $(\mathrm{k}=1.0223,=0.4938, \mu=0.0891)$ & -2.259 & -0.717 \\
Pishtaz & Error $(\mathrm{k}=1,=0.4993, \mu=0.9141)$ & -1.251 & -0.713 \\
Pishgam & Error $(\mathrm{k}=1.3908,=0.3535, \mu=0.0444)$ & -1.273 & -0.538 \\
Hafez & Cauchy $(=0.1745, \mu=0.0523)$ & -0.85 & -0.786 \\
Khobregan & Cauchy $(=0.06, \mu=0.17)$ & -1.911 & -0.812 \\
Razavi & Cauchy $(=0.2293, \mu=0.0586)$ & -2.483 & -0.942 \\
Sahm Ashna & Error $(\mathrm{k}=1.1445,=0.4993, \mu=0.0563)$ & -2.164 & -0.766 \\
Shadab & Cauchy $(=0.2155, \mu=0.0224)$ & -1.263 & -1.063 \\
Kaspian Mehr Iranian & Laplace $(=2.83, \mu=0.0227)$ & -0.793 \\
Yekom Iranian & Cauchy $(=0.0797, \mu=0.0597)$ & -0.401 \\
\hline
\end{tabular}

For Kupiec back testing, the data for the third quarter of 2011 were used as out of sample data to define VaR error in future data.

Table 3. Statistical results of Kupiec test for VaR using parametric and non-parametric approaches

\begin{tabular}{lcccc}
\hline \multirow{2}{*}{ Mutual Fund } & \multicolumn{2}{c}{ Garch(1,1) } & \multicolumn{2}{c}{ Monte Carlo } \\
\cline { 2 - 5 } & $=0.01$ & $=0.05$ & $=0.01$ & $=0.05$ \\
\hline Amin Global & 0.153 & 1.327 & 2.296 \\
Arian & 1.166 & 2.702 & 1.166 & 1.735 \\
Agah & 17.726 & 6.523 & 1.166 & 2.702 \\
Novin Bank & 1.166 & 0.253 & 6.523 \\
Tejarat Bank & 17.726 & 6.523 & 2.147 & 2.702 \\
Saderat Bank & 1.166 & 1.166 & 1.166 & 1.166 \\
Melli Bank & 1.166 & 0.004 & 1.166 & 1.166 \\
Bourse Bime & 1.735 & 0.395 & 0.395 & 5.077 \\
Boursiran & 1.735 & 1.328 & 1.735 & 1.328 \\
Pasargad & 0.624 & 0.802 & 2.296 & 14.851 \\
Pooya & 1.166 & 0.395 & 1.735 & 2.702 \\
Pishtaz & 0.004 & 4.45 & 1.166 & 1.328 \\
Pishgam & 0.328 & 1.328 & 1.328 & 14.384 \\
Hafez & 0.004 & 6.523 & 1.166 & 2.702 \\
Khobregan & 4.45 & 11.514 & 1.166 & 2.702 \\
Razavi & 1.166 & 1.328 & 1.735 & 24.285 \\
Sahm Ashna & 0.328 & 4.45 & 0.395 & 4.45 \\
Shadab & 2.702 & 6.523 & 1.166 & 2.702 \\
Kaspian Mehr Iranian & 1.735 & 0.328 & 1.166 & 0.004 \\
YekomIranian & 1.166 & 1.166 & 1.166 & 1.166 \\
\hline & & & & \\
\hline
\end{tabular}


According to Kupiec back testing, test statistics should follow chi-square distribution with 1 degree of freedom. Furthermore, based on two-way nature of the test, the statistics should be between 0.0009821 and 5.02389.

\section{Discussion}

Based on the results of Kupiec test, GARCH $(1,1)$ method produced correct prediction for 18 mutual funds at confidence level of $99 \%$ and had correct prediction for 15 mutual funds at confidence level of $95 \%$. Monte Carlo simulation method accurately predicted almost all funds at the confidence level of $0.99 \%$. It also correctly predicted 15 mutual funds at confidence level of 95\%. Therefore, the Monte Carlo simulation had better prediction results. This is in line with Gallsli \& Guesmi (2008).

As mentioned earlier, performance evaluation of mutual funds consists of returns and risk simultaneously. After calculating VaR as risk measure, an adjusted Sharpe ratio with average daily return was used to evaluate the performance of mutual funds. The results are shown in table 4 :

Table 4. Performance evaluation of mutual funds using adjusted Sharpe ratio with VaR

\begin{tabular}{clcclc}
\hline & Mutual Fund & $(\mathrm{R}-\mathrm{Rf}) / \mathrm{VaR}$ & & Mutual Fund & $(\mathrm{R}-\mathrm{Rf}) / \mathrm{VaR}$ \\
\hline 1 & Tejarat Bank & 0.094 & 11 & Melli Bank & 0.021 \\
2 & Pooya & 0.067 & 12 & Pasargad & 0.019 \\
3 & Pishtaz & 0.064 & 13 & Razavi & 0.018 \\
4 & Saderat Bank & 0.061 & 14 & Khobregan & 0.016 \\
5 & Boursiran & 0.056 & 15 & Arian & 0.015 \\
6 & Agah & 0.048 & 16 & Yekom Iranian & 0.014 \\
7 & Sahm Ashna & 0.046 & 17 & Pishgam & 0.013 \\
8 & Bourse Bime & 0.040 & 18 & Hafez & 0.010 \\
9 & Novin Bank & 0.031 & 19 & Kaspian Mehr Iranian & -0.002 \\
10 & Amin Global & 0.022 & 20 & Shadab & -0.012 \\
\hline
\end{tabular}

As shown in the table Tejarat Bank mutual fund occupied the first position while Shadab fund with a negative risk premium occupied the last position in sorting risk adjusted returns. Agah fund had the highest returns but it invested more in risky assets than in other funds with a VaR value of 1.085. So it occupied the sixth position, which means that the investors experience more risk to achieve a suitable return.

\section{Conclusion}

Value at Risk (VaR) is one of the important methods of risk calculation. In this study, GARCH and Monte Carlo simulation were used to calculate the VaR of Iranian mutual funds and Kupiec test was used to evaluate the two methods. The results indicated that that both models were almost efficient but in some funds, due to difference of data distribution function from normal distribution, parametric method produced higher errors at a high confidence level. The calculated VaR was used to evaluate performance of funds. Accordingly, the investors are recommended to use VaR as effective parameters for decision making purposes.

\section{References}

Alexander, C. (2008). Market Risk Analysis. Value-At-Risk Models, IV. John Wiley \& Sons Ltd.

Benninga, S. (2008). Financial Modeling (3rd ed.). London, England: The MIT Press.

Białkowskia, J., \& Otten, R. (2011). Emerging market mutual fund performance: Evidence for Poland. North American Journal of Economics and Finance, 22, 118-130. http://dx.doi.org/10.1016/j.najef.2010.11.001

Bollerslev, T. (1986). Generalized Autoregressive Conditional Heteroskedasticity. Journal of Econometrics, 31, 307-327. http://dx.doi.org/10.1016/0304-4076(86)90063-1

Bryant, L. L., \& Liu, H. C. (2011). Mutual fund industry management structure, risk and the impacts to shareholders. Global Finance Journal, 22, 101-115. http://dx.doi.org/10.1016/j.gfj.2011.10.002

Choudhry, M. (2006). An Introduction to Value-At-Risk (4th ed.). John Wiley \& Sons Ltd.

Chretien, S., \& Coggins, F. (2010). Performance and conservatism of monthly FHS VaR: An international 
investigation. International Review of Financial Analysis, 19, 323-333. http://dx.doi.org/10.1016/j.irfa.2010.08.006

Cullen, G., Gasbarro, D., \& Monroe, G. S. (2012). Changes to mutual fund risk: Intentional or mean reverting? Journal of Banking \& Finance , 36, 112-120. http://dx.doi.org/10.1016/j.jbankfin.2011.06.011

Deb, S. G., \& Banerjee, A. (2009). Downside Risk Analysis of Indian Equity Mutual Funds: A Value at Risk Approach. International Research Journal of Finance and Economics, (23), 216-230.

Eling, M. (2008). Does the Measure Matter in the Mutual Fund Industry? Financial Analysts Journal, 64(3). http://dx.doi.org/10.2469/faj.v64.n3.6

Engle, R. (1982). Autoregressive Conditional Heteroskedasticity with Estimates of the Variance of UK Inflation. Econometrica, 50, 654-708. http://dx.doi.org/10.2307/1912773

Feng, J. (2008). Evaluation The Performance of Chinese Mutual Funds: A Study of the Application of Value-at-Risk. (Unpublished master's thesis), University of Nottingham, Ningbo, China.

Gallsli, M. I., \& Guesmi, A. (2008). Value-at-Risk In Mutual Funds Which Methodology of Estimation. 2ème Conférence Euro-Africaine en Finance et Economie (CEAFE). Tunis.

Jorion, P. (2007). Value At Risk: The New Benchmark for Managing Financial Risk (3rd ed.). McGraw-Hill Companies.

Jorion, P. (2009). Financial risk manager handbook (5th ed.). Wiley finance series.

Khalili, A. M., \& Yeke, Z. A. (2010). Estimation of industrial market risk on basis of Value at Risk. Financial Studies Journal, 7(1), 47-72.

Mohammadi, S., Raee, R., \& Feiz, A. A. (2008). Calculation of parametric Value at Risk Using ARCH models in TSE. Financial Research Journal, 10(1\&2).

Raee, R., \& Saeedi, A. (2008). Introduction to financial Engineering and Risk management (3rd ed.). Tehran: SAMT.

Shahmoradi, A., \& Zangene, M. (2007). Calculating VaR for TSE indices with parametric methods. Economic Research Journal, 79, 121-149.

Weng, H., \& Trück, S. (2011). Style analysis and Value-at-Risk of Asia-focused hedge funds. Pacific-Basin Finance Journal, 19, 491-510. http://dx.doi.org/10.1016/j.pacfin.2011.05.002

Wiener, Z. (2012). The value of Value-at-Risk: A theoretical approach to the pricing and performance of risk measurement systems. Journal of Economics and Business, 64, $199-213$. http://dx.doi.org/10.1016/j.jeconbus.2012.02.002

Zhao, X., Wang, S., \& Lai, K. K. (2011). Mutual funds performance evaluation based on endogenous benchmarks. $\quad$ Expert Systems with Applications, 36, 3670. http://dx.doi.org/10.1016/j.eswa.2010.09.022

\section{Copyrights}

Copyright for this article is retained by the author(s), with first publication rights granted to the journal.

This is an open-access article distributed under the terms and conditions of the Creative Commons Attribution license (http://creativecommons.org/licenses/by/3.0/). 